Plant geology

\section{Changing weight of photosynthesis in the ocean}

\author{
from I. Gilmour
}

ON PAGE 216 of this issue Arthur et al. ${ }^{1}$ provide further evidence for the debate on what controls the carbon isotope composition of organic matter in marine sediments. The common photosynthetic pathways discriminate against the heavy carbon isotope $\left({ }^{13} \mathrm{C}\right)$, mainly as a result of a kinetic isotope effect inherent in carbon fixing reactions. As carbon dioxide dissolved in seawater contains more ${ }^{13} \mathrm{C}$ than atmospheric carbon dioxide, marine organic carbon is generally isotopically heavier - that is, ${ }^{13} \mathrm{C}$ enriched - than most land plants or terrestrial carbon. This has led to a general belief that the variations in the carbon isotope composition of organic matter in marine sediments provide a measure of the relative amounts of marine and terrestrially derived organic matter ${ }^{2,3}$. Arthur et al., however, now report an apparent reversal of this general trend in some marine sediments of Cretaceous and older ages ${ }^{1}$ (see figure). Using a second, independent, geochemical parameter to evaluate the source of the organic matter, they report carbon isotope values for rocks apparently containing mainly marine organic matter that are lighter (that is, more ${ }^{13} \mathrm{C}$-depleted) than those containing mainly terrestrial organic matter.

The parameter that Arthur et al. have measured is the hydrogen content of the organic matter, determined using the RockEval pyrolysis method, which provides a 'hydrogen index' related to the $\mathrm{H} / \mathrm{C}$ ratio in the organic matter ${ }^{4}$. Terrestrial organic matter has a lower $\mathrm{H} / \mathrm{C}$ ratio compared with marine organic matter because of the presence of lignin. This material, which gives land plants their 'woody' characteristic but is not found in marine algae, has a low $\mathrm{H} / \mathrm{C}$ ratio, reflecting its more aromatic chemical structure. Arthur et al., by plotting the carbon isotope composition of the organic matter against the 'hydrogen index' or $\mathrm{H} / \mathrm{C}$ ratio, relate organic carbon isotope values to the chemical composition of the organic matter, which in turn is dependent on the relative contributions of marine or terrestrial material. Using this approach, they are able to demonstrate that for Cretaceous and older organic rich sequences a negative correlation is commonly found, suggesting that the lightest carbon isotope values are related to chemical compositions that indicate the greatest contributions of marine organic matter. For the more recent Cenozoic sediments, they observe either a positive correlation or no correlation, reflecting the 'normal' isotope variations between marine and terrestrial materials and purely marine organic matter, respectively. Thus, pre-Cenozoic marine organic matter is anomalously depleted in ${ }^{13} \mathrm{C}$ by around 5 to 7 parts per thousand compared with marine organic matter in more recent sediments.

Anomalous ${ }^{13} \mathrm{C}$ depletions in ancient sediments are fairly common, particularly in Precambrian sediments ${ }^{5-7}$ where different carbon cycling pathways, notably those based on methane, have been invoked to explain them. It is difficult to try to explain such anomalies in ocean sediments, where the organic matter is derived predominantly from phytoplankton that use carbon dioxide. Arthur et al. consider several possibilities for this anomaly. They discount diagenetic effects, which generally do

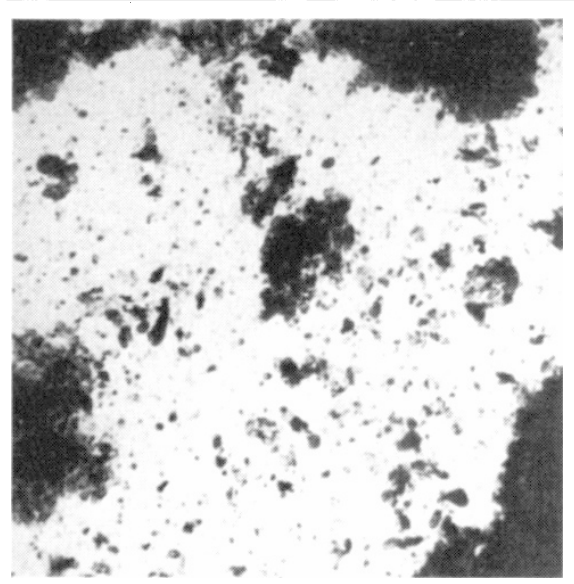

Organic material from a Cretaceous black-shale sequence from the Falklands Plateau, South Atlantic, which has revealed lighter carbon isotope composition than expected. The material is predominantly the remains of photosynthetic marine algae with minor amounts of material derived from the continents of the time. (Photo courtesy of I. Gilmour.)

not produce sufficiently large shifts in the carbon isotope composition of the organic matter. They also eliminate, although not totally, the possibility that changes in the carbon isotope composition of the organic matter reflect changes in the dominance of marine phytoplankton groups because this explanation is not supported by the Cenozoic palaeontological record. The three remaining possibilities all relate to one factor, the level and isotope composition of dissolved carbon dioxide in the oceans and its possible effect on photosynthesis. The authors eliminate a secular variation in carbon isotopes because the average Cretaceous carbonate is about 1.5 parts per thousand heavier than modern pelagic carbonates, which would result in marine organic matter being heavier, not lighter. Thus, the favoured interpretation is as follows: increasing the carbon dioxide concentration in the oceans can have a pro()1985 Nature Publishing Group found effect on photosynthesis. Photosynthetic carbon isotope fractionation is maximized under conditions of high carbon dioxide availability ${ }^{8,9}$ and, as Arthur et al. point out, this would result in ${ }^{13} \mathrm{C}$ depletion of organic matter. An increase in carbon dioxide availability can be accomplished by reducing the ocean temperature, which increases the solubility of carbon dioxide. But the Creteaceous oceans were as warm, if not warmer, than presentday oceans. Thus, Arthur et al. argue that possible higher levels of atmospheric carbon dioxide during the Cretaceous, combined with lower levels of surface productivity, would have resulted in more available carbon dioxide and increased fractionation of the carbon isotopes found in marine plankton.

Are these intepretations correct? If so, then modern marine photosynthesis may be occurring under geologically unusual conditions. True or false, their approach is certainly on the right lines. By relating carbon isotope composition to $\mathrm{H} / \mathrm{C}$ ratio and hence to chemical structure, the relative contributions of marine and terrestrially derived material are better understood. However, the carbon isotope values obtained still represent an average of two components, whereas ideally the marine and terrestrial material should be resolved completely. Failing this, the approach adopted by Arthur et al. is certainly an improvement on merely measuring bulk carbon isotopes in isolation. The implication from this work is, as the authors suggest, that carbon isotope values alone are not reliable for organic matter provenance studies, particularly in pre-Cenozoic sediments.

The possibility of fairly substantial variations in marine carbon isotope values resulting from variable photosynthetic fractionation is worth much closer investigation. Positive carbon isotope shifts in carbonates during the Cretaceous could represent increased oceanic productivity that uses up more of the lighter isotope ${ }^{10}$. The work of Arthur et al. could upset some of the widely accepted ideas for models of the carbon cycle. Clearly, more detailed work is required, but merely taking bulk carbon isotope values of organic matter in sediments in isolation is not going to help solve the problem.

\footnotetext{
I. Arthur, M.A., Dean, W.E. \& Claypool, G.E. Nature 315 $216(1985)$

2. Sackett, W.M. Mar. Geol. 2, 173 (1964).

3. Hedges, J.1. \& Parker, P.L. Geochim. cosmochim. Actu 40, 1019 (1976)

4. Espitalie, J. et al. Rev. Inst. Francais du Petrole 32, 23 (1977).

5. Schoell, M. \& Wellmer F.W. Nature 290, 696 (1981).

6. Hayes, J.M., Kaplan, I.R. \& Wedeking, K.W. in Earth's Early Biosphere (ed. Schopf, J.W.) (Princeton Univ. Press, 1983).

Gilmour l., Gibson, E.K., Abell, P.L \& Pillinger C.T. Terra Cognita 5, 145 (1985)

Cognita 5, 145 (1985).

8. Deuser, W.G., Degens, E.T. \& Guillard, R.R.L. Geochim cosmochim. Acta 32, 657 (1968).

9. Wong, W.W.\& Sacket, W.M. Geochim. cosmochim. Acta 42, 1809 (1978).

10. Weissert, H.J., McKenzie, J.A. \& Channell, J.E.T. Terra Cognita 5, 111 (1985)
}

I. Gilmour is in the Department of Earth Sciences, The Open University, Milton Keynes, Buckinghamshire $M K 76 A A, U K$. 